\title{
Article \\ Methodology for the Concept Design of Locally Reinforced Composites
}

\author{
Julius Moritz Berges* $*$, Georg Jacobs $\mathbb{1}$, Sebastian Stein (1) and Jonathan Sprehe \\ Institute for Machine Elements and Systems Engineering, RWTH Aachen University, Eilfschornsteinstraße 18, \\ 52062 Aachen, Germany; georg.jacobs@imse.rwth-aachen.de (G.J.); sebastian.stein@imse.rwth-aachen.de (S.S.); \\ jonathan.sprehe@imse.rwth-aachen.de (J.S.) \\ * Correspondence: julius.berges@imse.rwth-aachen.de; Tel.: +49-241-80-90878
}

check for updates

Citation: Berges, J.M.; Jacobs, G.; Stein, S.; Sprehe, J. Methodology for the Concept Design of Locally Reinforced Composites. Appl. Sci. 2021, 11, 7246. https://doi.org/ 10.3390/app11167246

Academic Editor: César M A. Vasques

Received: 7 July 2021

Accepted: 4 August 2021

Published: 6 August 2021

Publisher's Note: MDPI stays neutral with regard to jurisdictional claims in published maps and institutional affiliations.

Copyright: (c) 2021 by the authors. Licensee MDPI, Basel, Switzerland. This article is an open access article distributed under the terms and conditions of the Creative Commons Attribution (CC BY) license (https:// creativecommons.org/licenses/by/ $4.0 /)$.
Abstract: Locally load-optimized fiber-based composites, the so-called tailored textiles (TT), offer the potential to reduce weight and cost compared to conventional fiber-reinforced plastics (FRP). However, the design of TT has a higher complexity compared to FRP. Current approaches, focusing on solving this complexity for multiple objectives (cost, weight, stiffness), require great effort and calculation time, which makes them unsuitable for serial applications. Therefore, in this paper, an approach for the efficient creation of simplified TT concept designs is presented. By combining simplified models for structural design and cost estimation, the most promising concepts, regarding the cost, weight, and stiffness of TT parts, can be identified. By performing a parameter study, the cost, weight, and stiffness optima of a sample part compared to a conventional FRP component can be determined. The cost and weight were reduced by $30 \%$ for the same stiffness. Applying this approach at an early stage of product development reduces the initial complexity of the subsequent detailed engineering design, e.g., by applying methods from the state of the art.

Keywords: fiber reinforced composites; mechanical design; product development; multi-objective design; modelling; simulation

\section{Introduction}

Composites from fiber reinforced plastics (FRP) offer high weight-saving potentials compared to isotropic materials. Due to their superior density-specific stiffness and strength, FRP are highly suitable for lightweight applications [1]. The distinctive anisotropic behavior of continuous fibers can be utilized to design load-optimized structures. To make the most of the fiber's mechanical properties, they must be locally and congruently aligned with the component's principal stresses [2]. Manipulating the fiber paths in a manner to follow the local load-paths inside the FRP component offers the opportunity for, the so-called, tailored textiles (TT). The concept of TT is to optimize the layup and fiber orientations, considering the local stress magnitude and local orientation. By applying fibers only where structurally necessary, the material usage, and hence weight and cost, can be reduced by $30 \%$ compared to conventional FRP design strategies [3].

TT aim for low manufacturing costs by combining surface covering fabrics (baselaminate) and local fiber reinforcements, such as patches. The local reinforcements are applied to highly stressed areas, whereby the base-laminate carries a lower stress. In Figure 1 the potential for material savings using TT are shown.

Observing the stress distribution of a shear loaded component (Figure 1a,b), it is apparent that only a small area is highly stressed. Designing the component according to the maximum stress $\sigma_{\text {Max }}$, results in a large demand for material. For TT, the design stress of the whole surface covering base-laminate is reduced from $\sigma_{\mathrm{Max}}$ to $\sigma_{\text {Threshold }}$ by setting a limit value for the stress (stress threshold). The usually small reinforcements are applied locally, where high stresses above the limit of $\sigma_{\text {Threshold }}$ occur. Hence, the total material demand can be reduced using TT. 
(a)

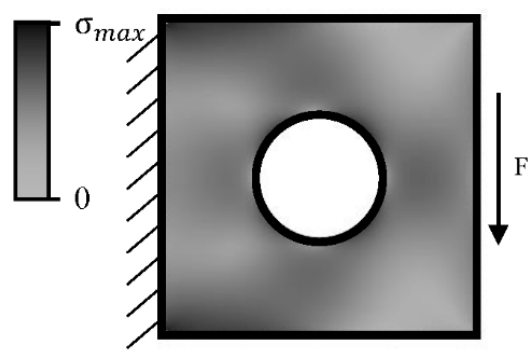

(b)

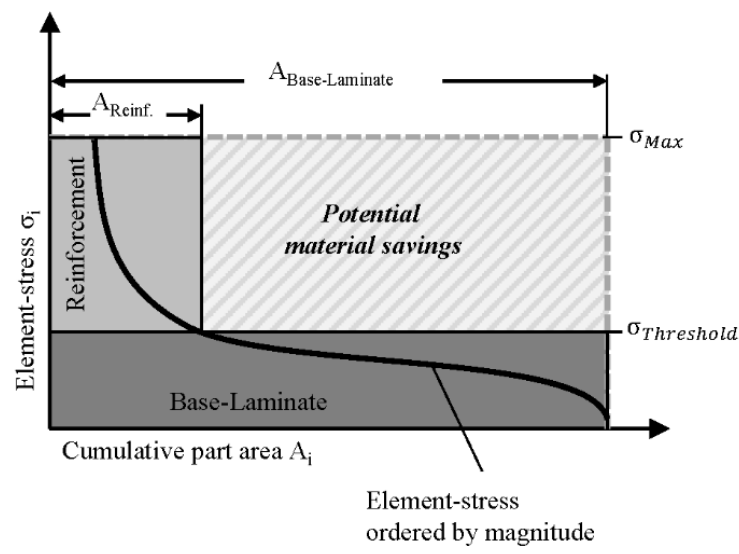

(c)

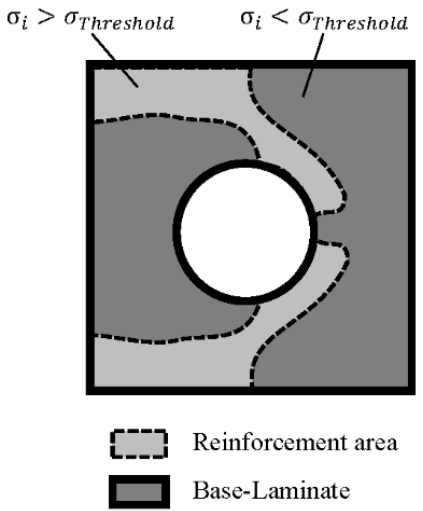

Figure 1. In (a), the stress distribution for a shear loaded component is given. $\sigma_{\text {Max }}$ denotes the maximum stress of the entire component. The element-stresses are ordered by their magnitude in (b). When splitting into base-laminate and reinforcements by the stress threshold, the total material demand is reduced. The reinforcement area is derived by all elements with element-stress $\sigma_{\mathrm{i}}>\sigma_{\text {Threshold }}$ as demonstrated in (c).

However, the appropriate choice of threshold (stress threshold), for splitting into high and low stress, is currently unknown, since it depends on both mechanical and economic aspects, which are discussed as follows.

The base-laminate consists of semi-finished goods, based on conventional textiles, which can be produced cost-efficiently. However, the production of many, typically small, reinforcements is associated with a lower material output rate, and thus leads to an increased weight-specific cost [4]. Therefore, from an economic point of view, as much stress as possible should be carried by the cost-efficient base-laminate, to use as few expensive reinforcements as possible.

In contrast, from a mechanical point of view, it makes sense to carry a larger share of the stress via the reinforcement area. The reinforcement area is divided into several clusters. These clusters have a constant fiber angle, to ensure the application of fiber composite manufacturing technologies (e.g., patches). However, the level of granularity of the clusters has a major influence on both the mechanical and economic properties of the TT. Continuously following the local principal stress orientations leads to the best mechanical properties, but would also require many small clusters, resulting in high manufacturing costs (Figure 2c) [4-6]. When using fewer but larger clusters with constant homogenized angles, the costs can be reduced (Figure $2 b$ ). However, the angle deviation of the homogenized angle in comparison to the element-wise optimal orientation of the principal stress (deviation factor) is high, and thus the mechanical properties are simultaneously reduced.

Several approaches for the simultaneous consideration of the mechanical and economic properties of FRP are available in the literature [7-9]. The approaches use genetic algorithms for the complex optimization task [10-17]. The appropriate formulation of complex optimization problems and the algorithm operators, as well as the execution, require a high level of effort.

Other approaches deal with the design of the reinforcements. For instance, the load path method and $\mathrm{CAIO}_{\mathrm{OW}}$ deal with the identification of optimized fiber trajectories, to exploit FRP's full lightweight potential [18-20]. The mfkCode presents an approach of clustering similar elements, to consider manufacturing aspects [21]. These approaches mainly focus on the determination of optimum fiber paths and require personal-biased user inputs, such as starting values or specific algorithm parameters, and additional software tools for the visualization and manual selection of load paths. A complete reproducibility of results is not guaranteed. 
(a)

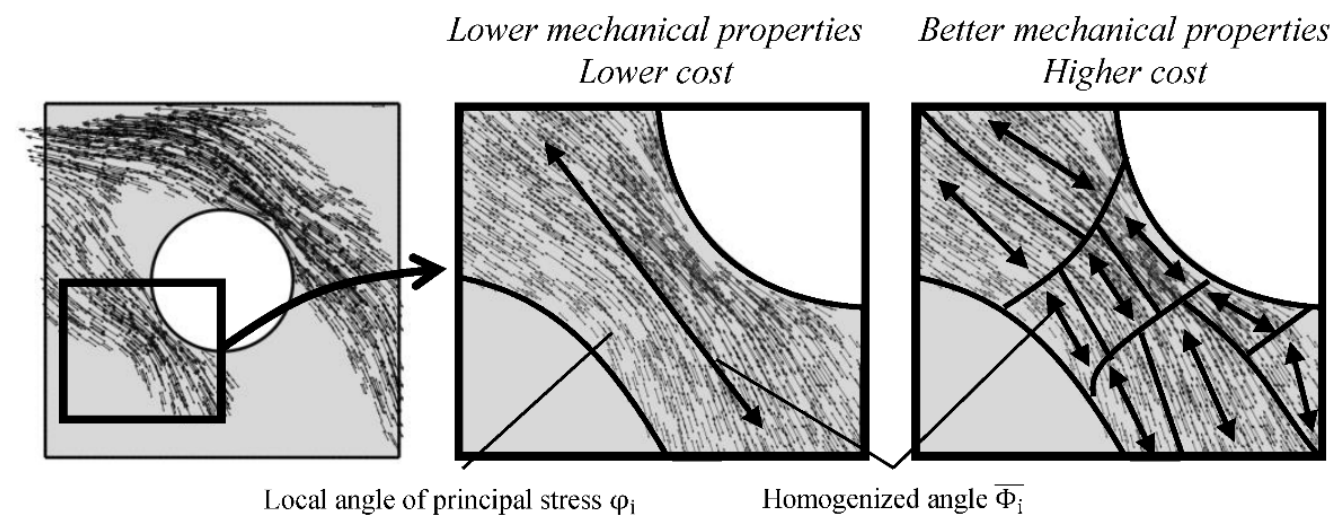

Figure 2. The deviation factor denotes the deviation of the angle between the homogenized angle and the local angles of the principal stress. (a) shows the overview of the relevant stresses and their local angles. Large deviation factors lead to lower mechanical properties but also fewer clusters and a lower cost (b). Lower deviation factors lead to good mechanical properties but also to more clusters and a higher cost (c).

Approaches for economic assessment generally focus on full-surfaced fabrics and not local reinforcements. Furthermore, the overall manufacturing process is considered, requiring a comprehensive set of input data [22,23]. Usually, the production planning, during which detailed manufacturing parameters are defined, is conducted in the later stages of the product development process [24]. To objectively determine the cost influences of the reinforcements for TT a simplified and more generic cost model, running on a minimal parameter set, is necessary.

In order to overcome the mentioned deficits, this paper presents a novel simplified and parameterized mechanical model (Section 2.1) and a simplified economic model (Section 2.2). The mechanical model creates simplified concepts for TT based on a single isotropic finite element analysis (FEA). The economic model is capable of estimating the costs of these simplified concepts. However, the stress threshold and deviation factor must be chosen depending on the specific application, to ensure an optimum cost, weight, and stiffness. Thus, by combining both models, optimized concepts of TT, regarding the trade-off between stiffness, weight, and cost can be realized, without causing numerous iteration loops in product development.

Applying this approach during the concept development for composite parts allows creating different concepts within a short period of time and forms a basis for decisionmaking, e.g., to decide if utilizing TT is appropriate for a specific application. Hence, the total development time for TT components can be further decreased, by reducing the initial complexity, and resulting in faster product development.

The main novelty of this approach is characterized by the efficient generation of simplified concepts for TT, based on an isotropic FEA and the stress tensor, and without requiring complex optimization algorithms.

The approach is validated in Section 3 using a generic demonstration example and by performing a parameter study for different stress thresholds and deviation factors, to determine the optimum weight, cost, and stiffness of a TT part compared to a conventional FRP part.

\section{Approach and Models}

In Section 2, the theoretical principles of the mechanical (Section 2.1) and economic (Section 2.2) models are presented. For the mechanical model, a special focus is given to the main parameters: stress threshold and deviation factor. The economic model enables the cost estimation of TT for base-laminate and reinforcements, depending on their size and quantity. The models are applied in Section 3 to a demonstration example, in order 
to examine feasible stress thresholds and deviation factors with regard to optimum cost, stiffness, and weight.

\subsection{Mechanical Model}

In Section 1 it was pointed out that the mechanical model needs to be already applicable in the concept phase, in which limited information is usually available. The following approach satisfies these requirements, as no additional data is required, except for the part dimensions, load case, and material data, as well as the main parameters of stress threshold and deviation factor (see Section 3). Furthermore, this mechanical model can be automatically executed, to rapidly generate a reproducible concept.

The mechanical model calculates the location, shape, and proposed fiber angles of reinforcements, as well as information about the design stress for the base-laminate as outputs. The detailed steps performed in this model are shown in Figure 3, and described as follows.

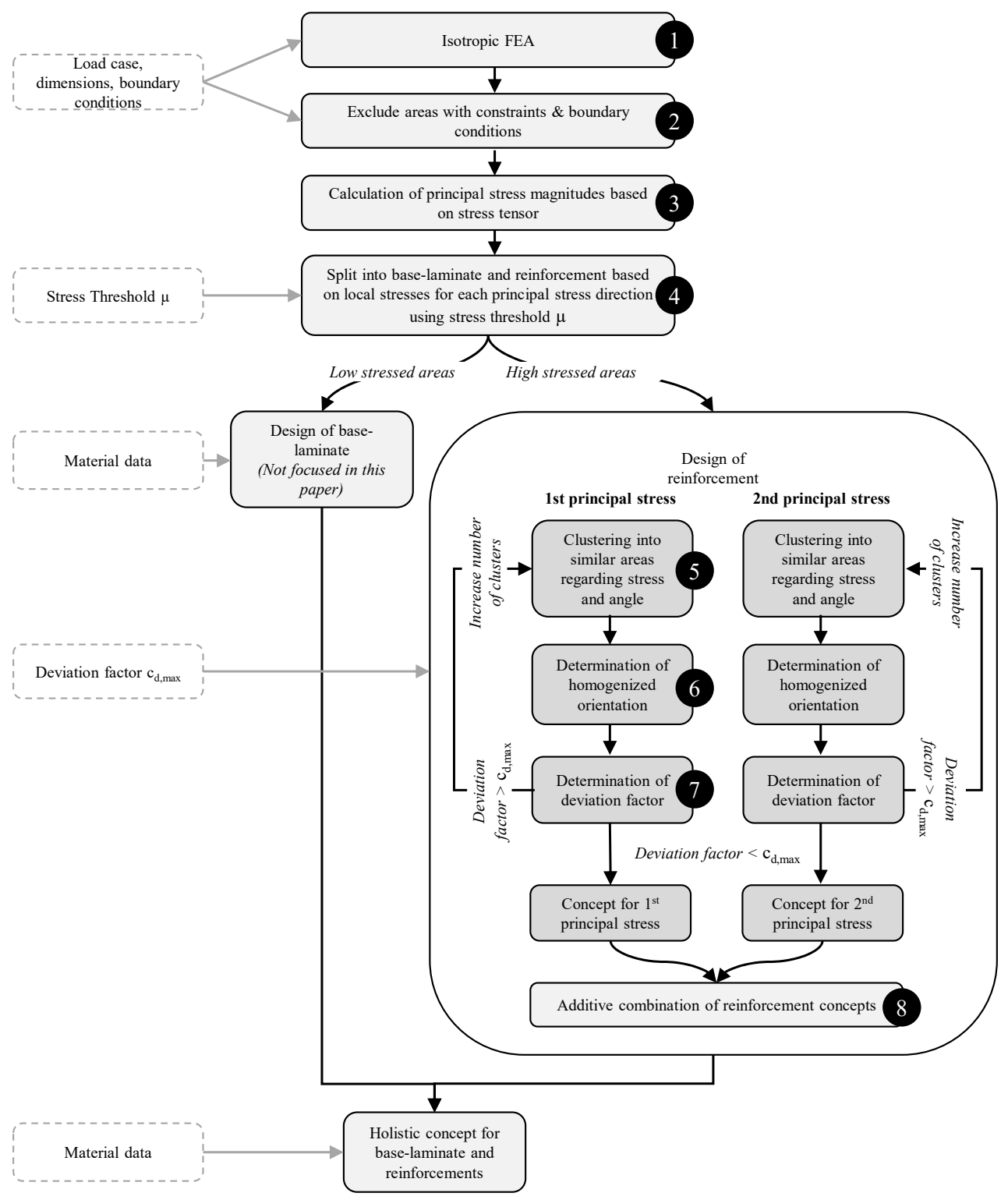

Figure 3. Illustration of the key steps performed in the mechanical model.

The basis for all the subsequent steps is an isotropic FEA of the initial geometry (step 1). Although the final material is anisotropic, it is mandatory to start the process with an isotropic material, since the load paths and corresponding principal stress angles need 
to be determined without being influenced by the anisotropic material. If an anisotropic material (i.e., composite) is applied in this step, an initial fiber orientation needs to be defined manually, which significantly influences the load paths depending on the user input [25-27].

After performing the FEA, areas near boundary conditions, such as screw holes, are excluded from further analysis (step 2). For these areas, prefabricated and predefined catalogue elements, such as patches, are recommended [1]. For the remaining areas, the magnitudes of principal stresses, in the 1st and 2nd principal stress directions, are calculated from the stress tensor for each element (step 3).

The mechanical model focuses on planar 2D components, thus it is assumed that the 3rd principal stress direction can be omitted. Tailored textiles consist of a surface-covering base-laminate (usually fabrics) and local fiber patches (reinforcements). The split into baselaminate and reinforcements is performed in step 4 , based on the parameter stress threshold $\mu(0 \%<\mu<100 \%)$ and the maximum stress in the entire component $\sigma_{\max }$. Elements with stresses below the limit $\sigma_{\max } \cdot(100 \%-\mu)$ are defined as base-laminate, elements above the limit are defined as reinforcements. The higher the value of the stress threshold chosen, the more of the stress is carried by the reinforcements.

Figure 4 shows an example for $\mu=40 \%$ and $\mu=60 \%$. For $\mu=40 \%$, the highest $40 \%$ of the stresses are carried by the reinforcements and the lowest $60 \%$ by the base-laminate. For $\mu=60 \%$, respectively, the highest $60 \%$ are carried by the reinforcements and the other $40 \%$ by the base-laminate. This characteristic can be described by $\sigma_{\mathrm{i}}=\sigma_{\mathrm{b}}+\sigma_{\mathrm{r}}$, where $\sigma_{\mathrm{i}}$ denotes the elementwise stress and $\sigma_{\mathrm{b}}$ and $\sigma_{\mathrm{r}}$ the design stress for the base-laminate and reinforcements.

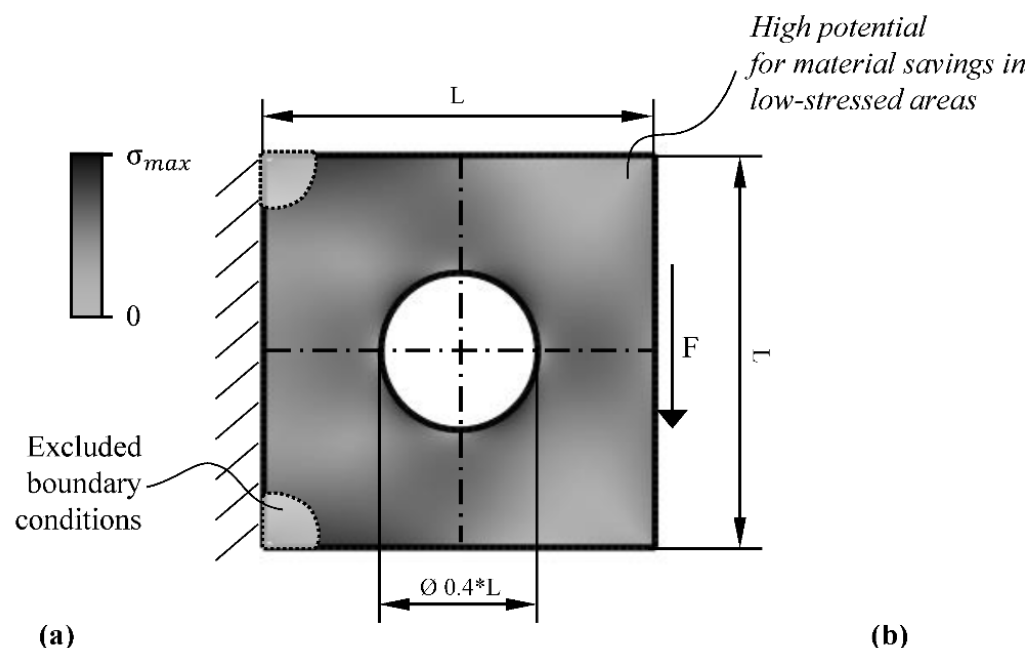

$\mu=40 \%$

Base-Laminate

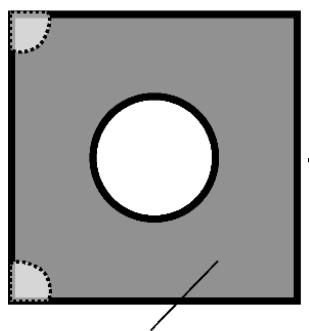

$0<\sigma_{b} \leq \sigma_{\max }(100 \%-\mu)$
Reinforcements

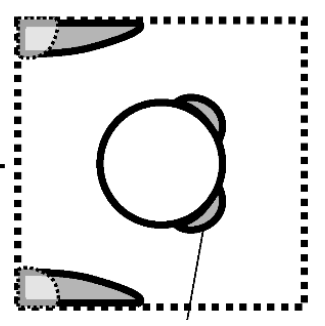

$0<\sigma_{r}<\sigma_{\max } \cdot\left(\frac{\mu}{100 \%}\right)$

$\sigma_{i}=\sigma_{b}+\sigma_{r}$

$\mu=60 \%$

Base-Laminate

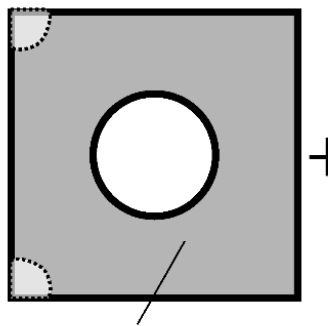

$0<\sigma_{b} \leq \sigma_{\max }(100 \%-\mu)$
Reinforcements

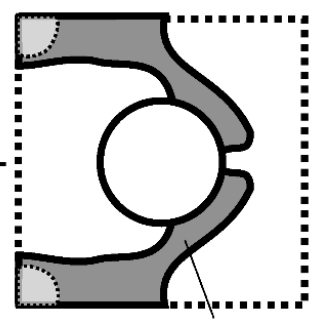

$0<\sigma_{r}<\sigma_{\max } \cdot\left(\frac{\mu}{100 \%}\right)$

$$
\sigma_{i}=\sigma_{b}+\sigma_{r}
$$

Figure 4. Schematic illustration of the split into base-laminate and reinforcement area for stress thresholds $\mu=40 \%$ (a) and $\mu=60 \%(\mathbf{b})$. 
The area of the reinforcements depends on the stress threshold, whereas the baselaminate always covers the entire surface of the part. However, there is normally no linear relationship, since the stress distribution in the parts is usually not linear (e.g., Figure 1b). Thus, doubling the stress threshold does not generally lead to a doubling of the reinforced surface area.

The following steps focus on designing the reinforcements, since the base-laminate can be designed using conventional methods. From a mechanical point of view, the best reinforcement can be achieved by locally rotating each element, with the characteristic orthotropic material behavior of FRP, in the direction of the maximum principal stress $[6,28]$.

However, from a technological and economic point of view, these small clusters and incremental changes in material properties are not feasible for FRP components, considering economic and manufacturing aspects [4]. Similarly, the clustering and homogenization of too large areas is mechanically unreasonable due to the high deviation from the mechanically optimal orientation of the orthotropic material $[5,6]$. Thus, to satisfy both the economic and the mechanical domains, the most suitable number of clusters with a constant angle must be determined. Therefore, elements with similar properties regarding the location and local orientation of the principal stresses are clustered within the reinforced area using the cluster algorithm k-means [29] (Step 5, Figures 3 and 5). The entire reinforcement area is thus divided into clusters. Each of the principal stress directions is considered individually, since each principal stress direction results in different reinforcement areas.

(a)

Angles of principal stress direction 1

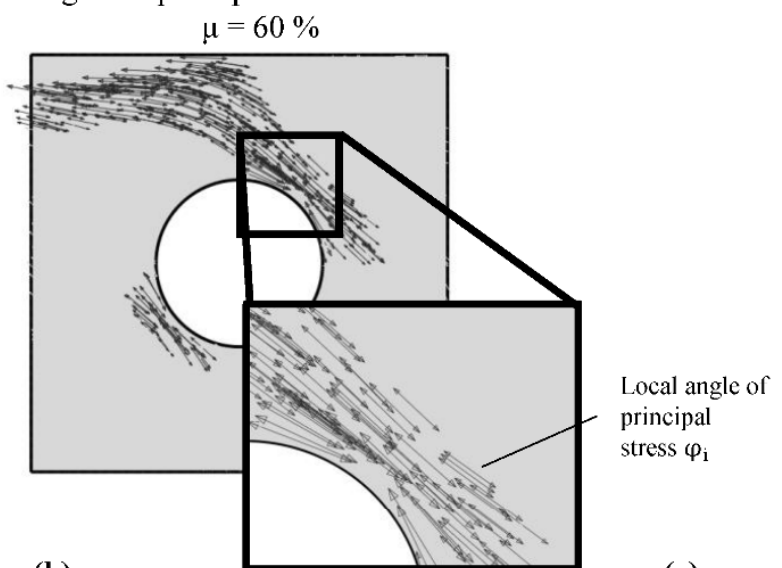

(b)

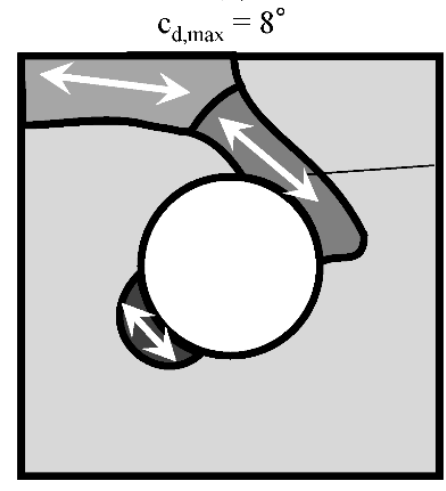

(c)

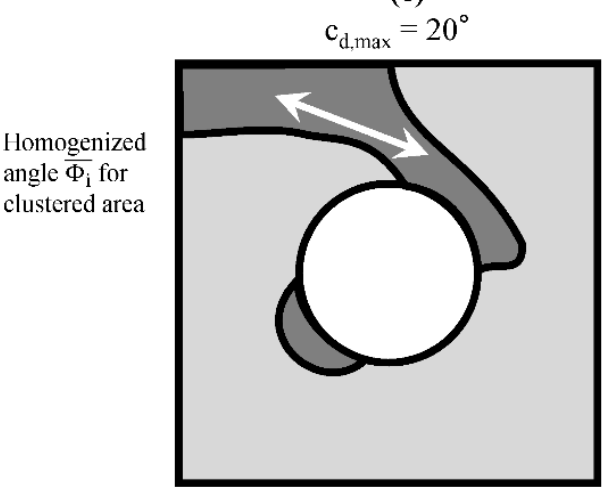

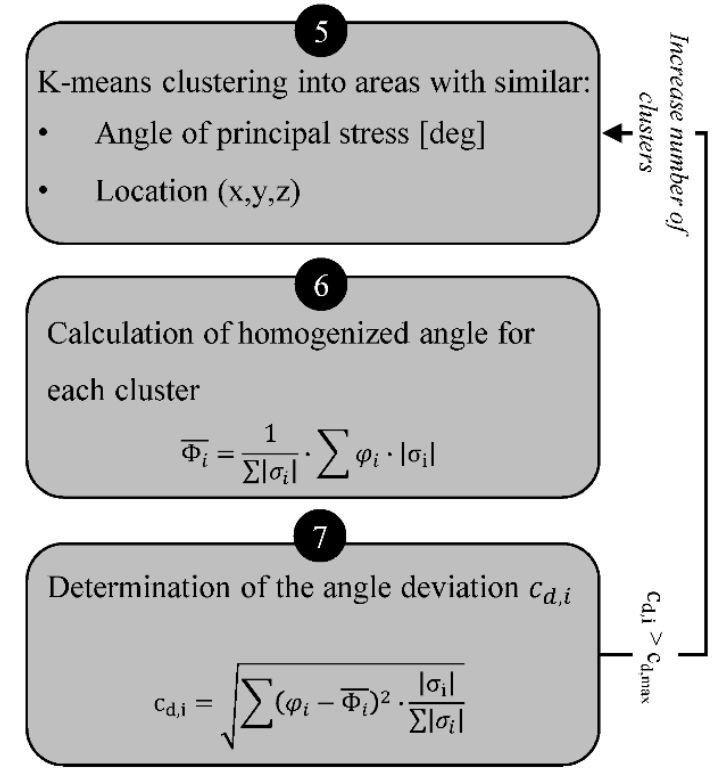

Calculation of homogenized angle for

$$
\overline{\Phi_{i}}=\frac{1}{\sum\left|\sigma_{i}\right|} \cdot \sum \varphi_{i} \cdot\left|\sigma_{\mathrm{i}}\right|
$$

Determination of the angle deviation $c_{d, i}$

$$
\mathrm{c}_{\mathrm{d}, \mathrm{i}}=\sqrt{\sum\left(\varphi_{i}-\bar{\Phi}_{i}\right)^{2} \cdot \frac{\left|\sigma_{\mathrm{i}}\right|}{\sum\left|\sigma_{i}\right|}}
$$

Figure 5. Clustering of reinforcement area into multiple areas with similar angles of principal stresses using deviation factor $c_{d, \max }$. (a) Shows the resulting principal stress directions for $\mu=60 \%$. In $(b, c)$ the calculated cluster angles are shown for $c_{d, \text { max }}=8^{\circ}$ and $20^{\circ}$. For $c_{d, \text { max }}=8^{\circ}$ three clusters are required, for $c_{d, \text { max }}=20^{\circ}$ only one cluster is required.

For each cluster, a homogenized angle and a deviation factor are calculated (Step 6 Figure 5). The homogenized angle $\overline{\Phi_{i}}$ is the mean angle of the principal stress angles $\varphi_{\mathrm{i}}$ in the respective cluster, weighted by their local stress. For the calculation of the homoge- 
nized angle, higher stressed elements are also associated with a higher weight, due to the higher priority and greater demand for reinforcements (Step 6, Figure 5). The deviation factor $c_{d, m a x}$ is the maximum allowed deviation from the mechanically ideal angle and is consequently a measure of mechanical quality for the respective area. It is calculated by the stress-weighted standard deviation of the local element principal stress angles $\varphi_{\mathrm{i}}$ (Step 7, Figure 5). If the deviation factor exceeds the predefined value $c_{d, \max }$, the number of clusters is iteratively increased until the desired value is achieved. The higher the value of $c_{d, \max }$ chosen, the fewer clusters are required to satisfy this constraint (see Figures 2 and 5). However, the deviation from the mechanically optimal solution increases respectively [6].

The deviation factor and stress threshold are the main parameters of the model that control the trade-off between a mechanically optimal structure and economic efficiency. The parameter dependencies and interactions are examined in more detail in Section 3, as part of the analysis with different parts and load cases.

In the last step, the base-laminate and the reinforcement concepts of the 1st and 2nd principal stress directions are combined additively (step 8). It should be noted that the reinforcements of the principal stress directions 1 and 2 overlap in some areas. However, this behavior strongly depends on the specific dimensions, loads, and boundary conditions. The final results of this mechanical model are simplified concepts for the design of the baselaminate and reinforcements (clusters, dimensions, homogenized angles, etc.) as a function of the input parameters: stress threshold $\mu$ and the maximum deviation factor $c_{d, \max }$.

The presented approach primarily focuses on an increase in stiffness. The material thicknesses must be defined manually for each specific application. In the mechanical model, the mean stress is calculated for the base-laminate and each cluster within the reinforcement area, which can be used for an appropriate initial estimation of thickness values. To satisfy specific strength requirements, the layer thicknesses can then be estimated iteratively or by evolutionary algorithms [21,30].

\subsection{Economic Model}

The presented economic model aims for the cost estimation of composite structures in an early phase of the product development process. Within this economic model, only the manufacturing steps of cutting and stacking are considered, and subsequent steps such as preforming are not considered, since only plane and rectangular structures, as introduced in Section 2.1, are assessed within this paper. Subsequently, the cost model can be replaced by company-specific cost models. Available models from the state of the art are not applicable for TT, since they do not consider the split between base-laminate and reinforcements. Hence, a simplified approach for the estimation of TT costs is introduced. To unravel the economic influences of the previously introduced mechanical model, the same patch laying manufacturing method is considered, to ensure the comparability of the results. This model focuses only on the manufacturing of the fabric semi-finished product, including material costs, waste costs, cutting costs, and stacking costs (see Equation (1)).

$$
\mathrm{C}_{\text {total }}=\sum_{n}\left(\mathrm{C}_{\text {material }, \mathrm{n}}+\mathrm{C}_{\text {waste, } \mathrm{n}}+\mathrm{C}_{\text {cutting, } \mathrm{n}}+\mathrm{C}_{\text {stacking, } \mathrm{n}}\right)
$$

The subsequent manufacturing steps are assumed to be within the same cost range for each laminate concept, and therefore not given further consideration. The input parameters passed from the mechanical model are the material data and the dimensions of the reinforcements (reinforced area and number of clusters). Hence, only the relative cost-proportion between the different concepts is considered; the average costs for material, waste, cutting, and stacking are applied within the presented model. Stacking costs for a manual lay-up process can be described as labor costs, depending on the patch size. For example, smaller patches are easier to handle, but more working steps are required to cover a certain area compared to larger patches. This results in higher costs per area for small patches. By applying a best-fit curve to the empirical data collected within the research project "Tailored Composites", formula (2) can be deduced. Formula (2) allows 
calculating the patch size depending on stacking costs. The prepositioned factor, as well as the exponent, cover a constant cost share, resulting from the empirically measured stacking times required for certain patch sizes (see Figure 6).

$$
c_{\text {stacking }, i}=37.023 \cdot \mathrm{A}_{\text {patch }, i}{ }^{-0.685}
$$

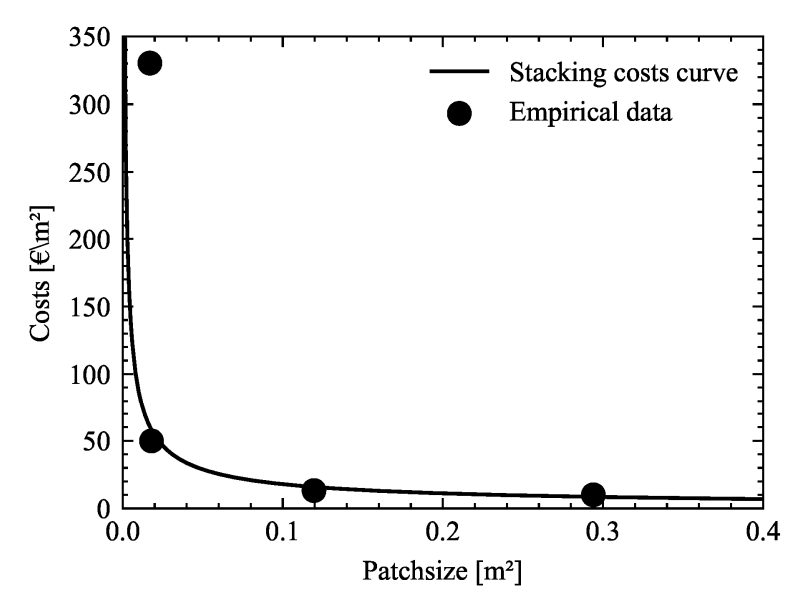

Figure 6. Costs are mapped to the patch size using Equation (2), resulting in high costs for small patches and low costs for large patches.

Waste costs are composed of an average general waste percentage of $5 \%$ and the cut-off resulting from trimming the fabric multiplied by the material density and costs (Equation (3)).

$$
\mathrm{C}_{\mathrm{i}, \text { Waste }}=\mathrm{C}_{\mathrm{i}, \text { Material }} \cdot \rho_{i} \cdot \mathrm{A}_{\mathrm{i}, \text { Waste }} \cdot\left(100 \%+\mathrm{c}_{\mathrm{i} \text {,percent_waste_general }}\right)
$$

The calculation of the waste area and hence the waste cost calculation, as presented in this paper, is applicable for any components made of a single or multiple rectangular fiber patches. However, within this approach a square-shaped demonstrator is considered (see Section 3), resulting in the trimmed waste of the inner circular cut-out and the outer cut-offs. The outer cut-offs are dependent on the fabric's fiber orientation relative to the cutting edges (c.f. Figure 7, Equation (4)). Assuming the reinforcement patches are orientated at $0^{\circ}$, only the general waste ratio is considered.

$$
\mathrm{A}_{\mathrm{i}, \text { Waste }}=\left(\text { width }_{\mathrm{i}, \mathrm{Ply}}{ }^{2}+\text { length }_{\mathrm{i}, \mathrm{Ply}}{ }^{2}\right) \cdot \sin \alpha \cdot \cos \alpha
$$

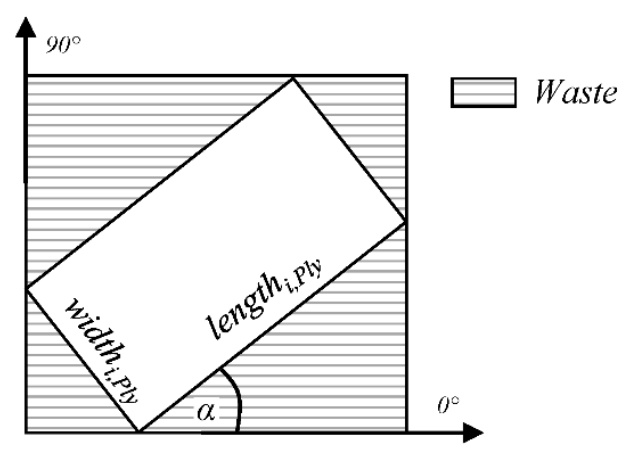

Figure 7. Calculation of material waste area for rectangular shapes for fiber angle $\alpha$, depending on the width and length of an FRP layer.

\section{Demonstration of the Approach}

In Section 3, the dependencies and interactions of the mechanical and economic models are investigated by analyzing a demonstration example, in Sections 3.1 and 3.2. 
The aim of these studies was the identification of suitable parameter settings for the main parameters of stress threshold and deviation factor, to achieve global optima in terms of the target values of stiffness, weight, and cost for simplified TT concepts.

Section 3.1 focuses on the analysis of the deviation factor $c_{d, \max }$, using only the mechanical model. For this purpose, the stress threshold is kept constant and the isolated influence of the deviation factor on the target values is examined. In Section 3.2, the influence of the stress threshold $\mu$ with different deviation factors $c_{d, \max }$ is examined. A TToptimized laminate is examined, and the target values are compared against a conventional reference laminate.

The studies were conducted on different parts and load cases. However, the results do not differ significantly. Therefore, the results are demonstrated only for a quadratic shell (length $\mathrm{L}=900 \mathrm{~mm}$ ) with a center hole $(\varnothing 360 \mathrm{~mm}$ ) and a shear load case (see Figure 8). This part has a fixed support on the left and a shear load $F_{\text {shear }}=100 \mathrm{~N} / \mathrm{mm}$ on the right edge. Table 1 shows the properties of the UD layer for all studies. Both mechanical and economic models were executed in Python, and the finite-element models were built and solved in ABAQUS.

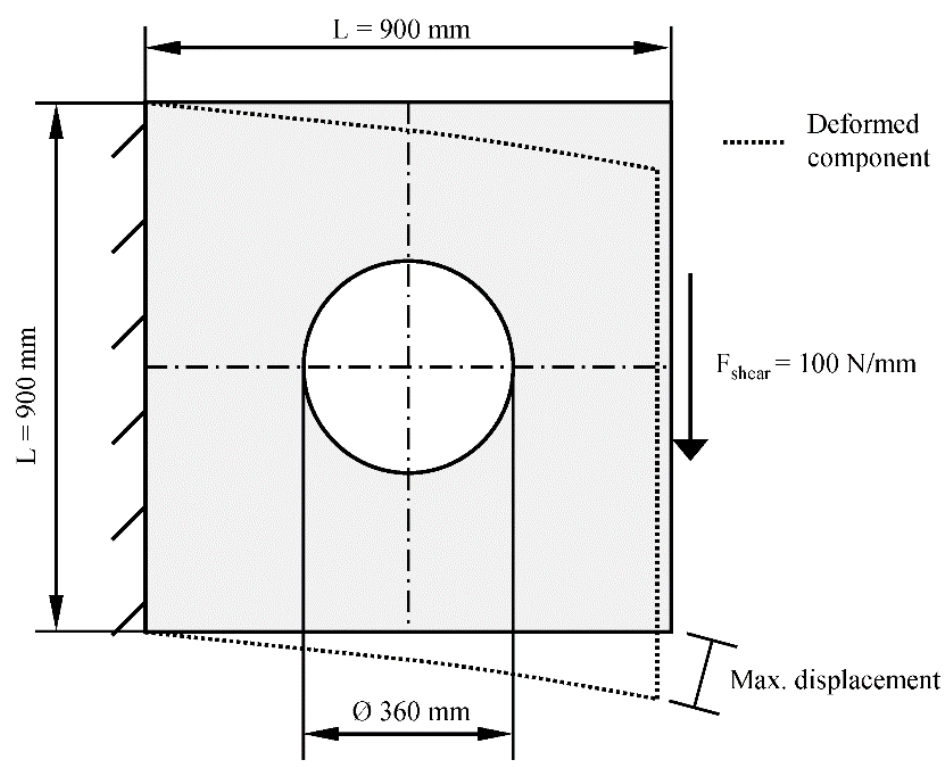

Figure 8. As a demonstration example, a simple quadratic shell with a center hole and a shear load case is examined. The deformed geometry is illustrated by the dotted line.

Table 1. Material properties of each unidirectional carbon/epoxy composite ply.

\begin{tabular}{cc}
\hline Parameter & Value \\
\hline $\mathrm{E}_{11}(\mathrm{GPa})$ & 138 \\
$\mathrm{E}_{22}(\mathrm{GPa})$ & 9.5 \\
$\mathrm{G}_{12}(\mathrm{GPa})$ & 5.2 \\
$v_{12}$ & 0.28 \\
$\rho\left(10^{3} \mathrm{~kg} / \mathrm{m}^{3}\right)$ & 1.6 \\
\hline
\end{tabular}

\subsection{Analysis of the Deviation Factor}

To analyze the effect of the deviation factor $c_{d, \max }$, a single layer was created by using a shell FE model and execution of the mechanical model, as presented in Section 2.1. Anisotropic material properties of a unidirectional layer (UD) (see Table 2) were then applied for each cluster, whereby the material orientations were provided by the mechanical model. 
Table 2. Cost, max. displacement, and weight of the reference laminate.

\begin{tabular}{cc}
\hline Parameter & Value \\
\hline Cost & $564.94 €$ \\
Max. displacement & $1.6 \mathrm{~mm}$ \\
Weight & $13,597 \mathrm{~g}$ \\
\hline
\end{tabular}

The stress threshold was set to a constant value of $\mu=100 \%$ and, hence, the entire part, except the excluded areas near to the constraints, is covered by reinforcements. The maximum principal stress was considered for each of the elements, and no distinction was made between 1st and 2nd principal stress. The relative displacement in respect to the maximum displacement, as well as the number of clusters as a function of the deviation factor, were examined. Figure 9 shows the results of the investigations.

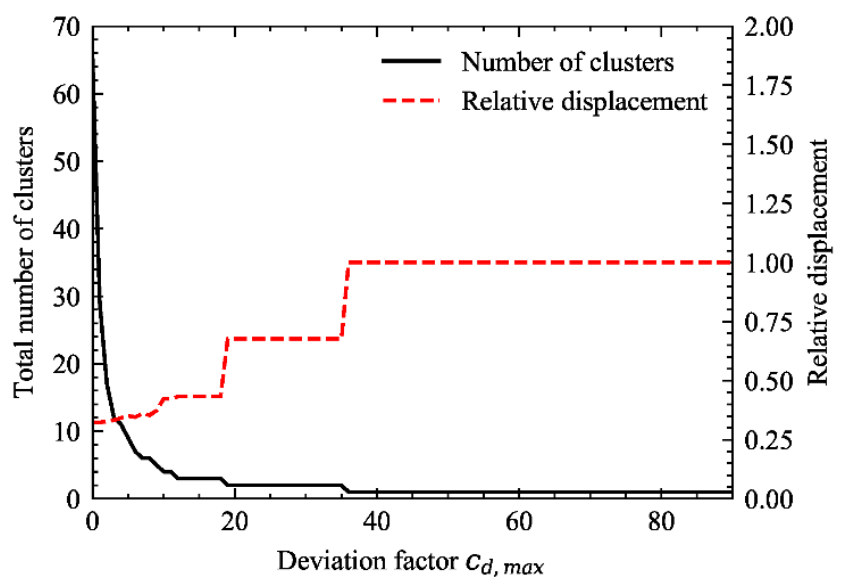

Figure 9. Total number of clusters that are required to satisfy the deviation factor $c_{d, \max }$ (black) and the corresponding relative displacement (red) in relation to the max. displacement.

For the demonstrator, a significant dependence of the relative displacement and the number of clusters from $c_{d, \text { max }}$ can be identified. For small deviation factors, e.g., $c_{d, \max }=1^{\circ}$, the relative displacement can be reduced by approx. $70 \%$. Concurrently, the number of clusters increases as the angular tolerance for each individual cluster factor decreases. The number of clusters is small for high deviation factors, since the angular tolerance is wider and more elements can be summarized in one cluster. It should be noted that a high deviation factor, at about $45^{\circ}$ or more, usually results in a single cluster (see Figure 10 $c_{d, m_{x}}=45^{\circ}$ ) and a homogenized angle for the entire part, which is effectively equivalent to a single UD-layer.

$$
C_{\text {.dmax }}=15^{\circ}
$$

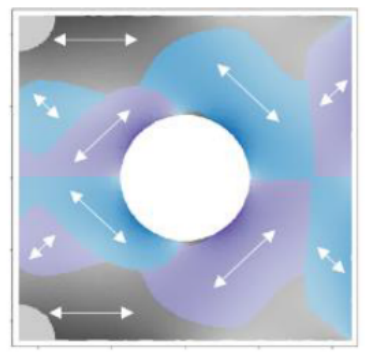

$$
C_{, \text {dmax }}=20^{\circ}
$$

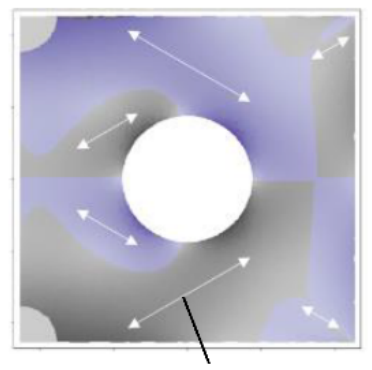

Homogenized angle $\overline{\Phi_{i}}$ for clustered area

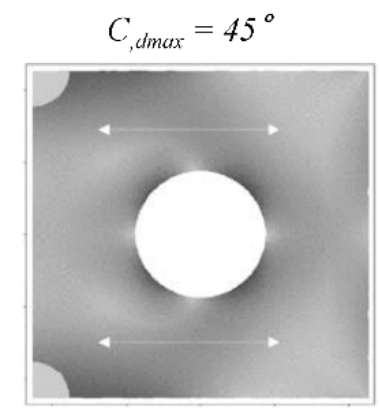

Figure 10. Resulting clusters for deviation factors of $c_{d, \max }=15^{\circ}, 20^{\circ}$, and $45^{\circ}$.

Both the displacement and the number of clusters change progressively with decreasing $c_{d, m a x}$. This behavior is caused by the fact that a maximum limit value is defined with 
$c_{d \text {,max }}$ for all clusters (refer Figure 5), although the actual deviation in several clusters is often significantly lower. Thus, many clusters typically achieve a lower deviation prior to that point. For values of $c_{d \text {,max }}$ up to approx. $10^{\circ}$, the effect of reducing the displacement is most significant. Below $10^{\circ}$, the displacement is only slightly reduced, while the number of clusters increases excessively. Economic factors must be considered in this context, as higher costs are to be expected for a large number of small clusters [4] (see Section 3.2).

\subsection{Analysis of the Deviation Factor and Stress Threshold}

The following section focuses on the effects of both deviation factor and stress threshold on the costs, displacement, and weight for the demonstration example given in Figure 8 . The reference laminate is defined by a symmetrical UD $60^{\circ} / 0^{\circ} /-60^{\circ}$ laminate with a layer thickness of $\mathrm{t}=2 \mathrm{~mm}$ (layer properties see Table 2). This lay-up was determined by analyzing the principal stress directions and is suitable for carrying the applied load cases, while having only small deformations. The cost, max. displacement, and weight of the reference laminate are shown in Table 2.

To ensure comparability, for the base-laminate of the TT optimized part, the same lay-up as the reference laminate is applied, while the thickness of each layer is reduced to $\mathrm{t} / 2=1 \mathrm{~mm}$.

Each reinforcement has a layer thickness of $\mathrm{t}=2 \mathrm{~mm}$ and is applied symmetrically on the top and bottom faces of the base-laminate. For principal stress directions 1 and 2 , the reinforcement areas and corresponding angles from the mechanical model are applied directly, as calculated by the mechanical model. As discussed in Section 2.1, the reinforcements for both principal stress directions might overlap. The maximum displacement, weight (base-laminate plus reinforcement), and costs are considered as target values. All values of the TT-optimized component are given as relative values, in relation to the reference laminate, where values below 1 indicate an enhancement compared to the reference laminate. The target values are analyzed for stress thresholds $\mu$ from $5 \%$ to $100 \%$ and deviation factors of $5^{\circ}, 10^{\circ}$, and $15^{\circ}$. The overall behavior of the target values, depending on the stress threshold, is shown in Figure 11, for a deviation factor of $5^{\circ}$.

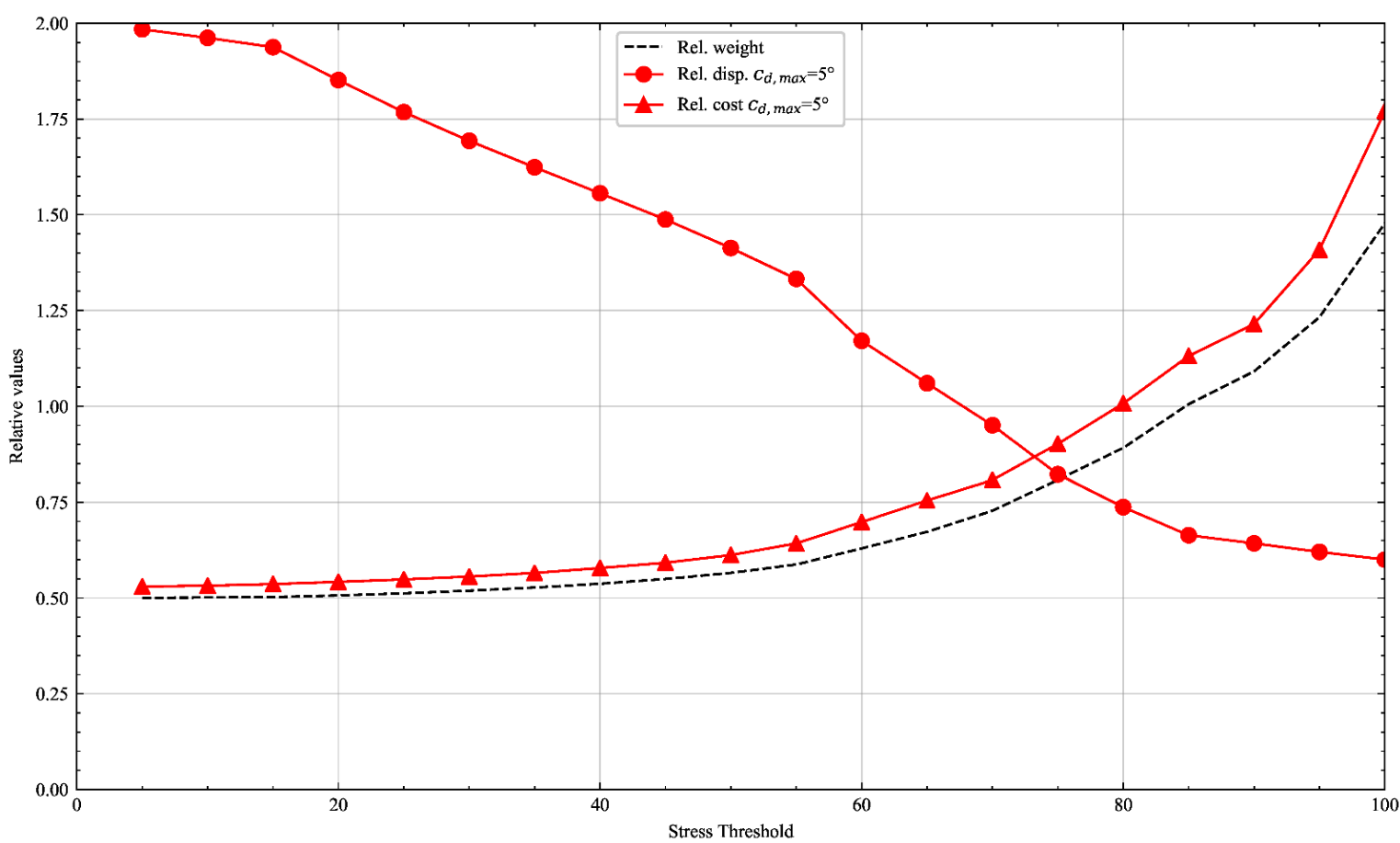

Figure 11. Results from both mechanical and economic models $\left(c_{d, \max }=5^{\circ}\right)$ for the demonstration example introduced in Figure 8. Cost, displacement, and weight from the tailored textiles component are given as relative values in relation to the reference laminate. 
In general, a contrary behavior of weight and costs, as well as of the max. displacement, can be observed. A decrease in the maximum displacement for high-stress thresholds occurs, due to an increase in the proportion of stress carried by the reinforcements. At the same time, costs rise as the component weight and the number of clusters increase.

For the TT component, the displacement, weight, and costs can be reduced compared to the reference laminate using the proposed mechanical and economic models. For low and high-stress thresholds, the TT component has a lower performance (values $>1$ ) than the reference laminate. In a range that is between approx. $67.5 \%$ and $85 \%$, the TT optimized part shows significantly better performance than the reference laminate (values $<1$ ).

In Figure 12, this feasible range is examined in more detail, giving the values for deviation factors of $5^{\circ}, 10^{\circ}$, and $15^{\circ}$.

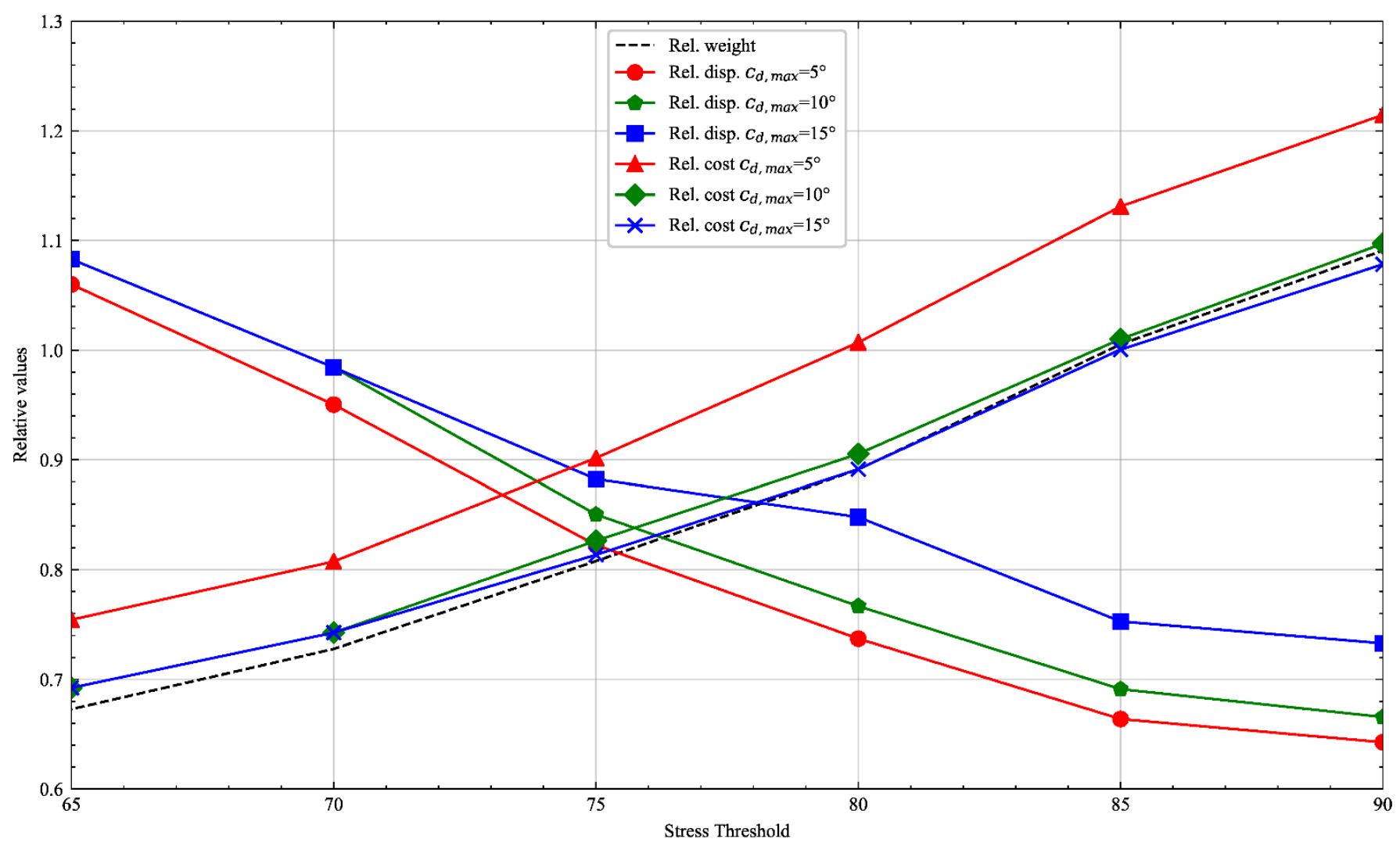

Figure 12. Relative cost, weight, and displacement for deviation factors of $5^{\circ}, 10^{\circ}$, and $15^{\circ}$ in relation to the reference laminate. Values below 1 indicate an improvement. The weight is equal for each case since it is defined only by the stress threshold, and therefore is independent from the deviation factor.

As an example for a deviation factor of $10^{\circ}$ : for the same displacement as the reference laminate, weight and costs are reduced by approx. 30\% with TT at $\mu \approx 67.5 \%$ for $c_{\mathrm{d}, \max }=10^{\circ}$. The displacement is reduced by approx. $30 \%$ for the same weight and costs at $\mu \approx 85 \%$ for $\mathrm{c}_{\mathrm{d} \text {, max }}=10^{\circ}$. Between these points, any desired interstate can be chosen. As expected, low deviation factors show the lowest maximum displacement. However, simultaneously, the costs increase significantly. The maximum difference in cost and displacement is about $20 \%$ between $c_{d, \max }=5^{\circ}$ and $c_{d, \max }=15^{\circ}$.

Figure 13 illustrates the resulting angles for the 1st principal stress clusters at $\mu \approx 50 \%$, $\mu \approx 67.5 \%$, and $\mu \approx 85 \%$ for $c_{d, \max }=5^{\circ}, c_{d, \max }=10^{\circ}$, and $c_{d, \text { max }}=15^{\circ}$. The principal stress direction 2 shows the same behavior, in a mirrored pattern, and is therefore not discussed here. The base laminate covers the entire surface, while the reinforced area increases with the increasing stress threshold. For smaller deviation factors, the mechanical model calculates numerous small clusters $(a, b, c)$, whereas high deviation factors result in 
fewer but larger clusters $(\mathrm{g}, \mathrm{h}, \mathrm{i})$. The increasing number of small clusters is responsible for the increased costs.

(a)

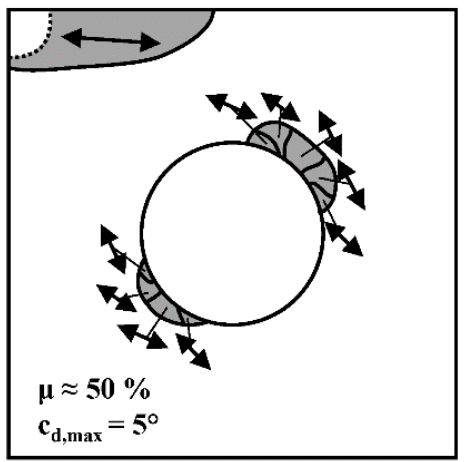

(d)

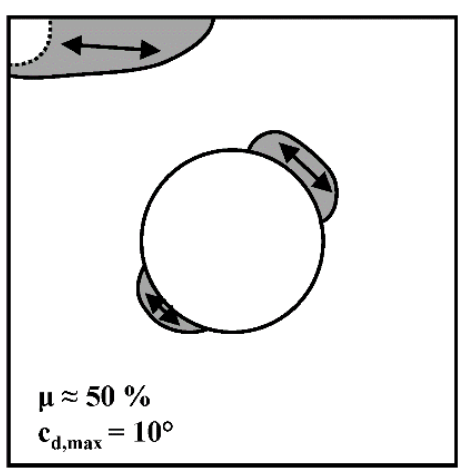

(g)

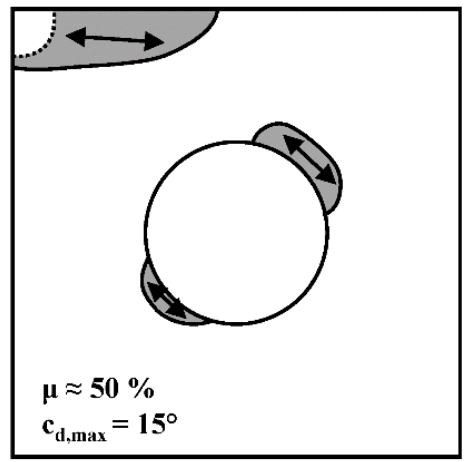

(b)

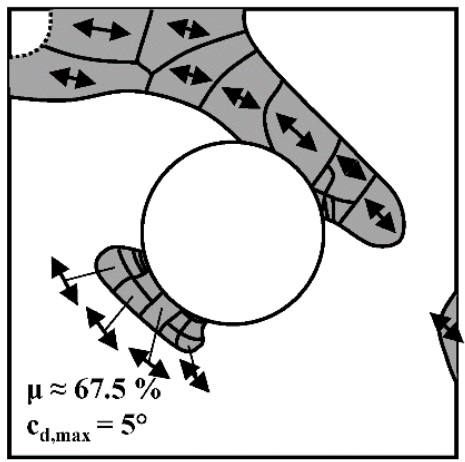

(e)

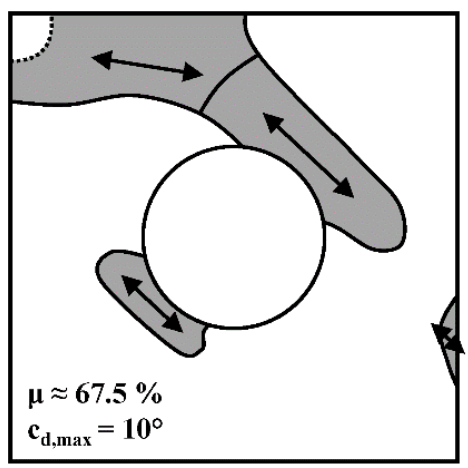

(h)

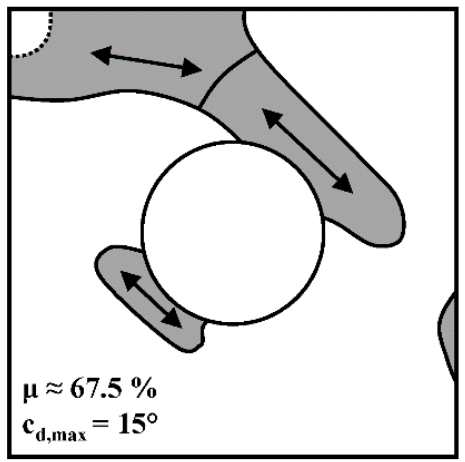

(c)

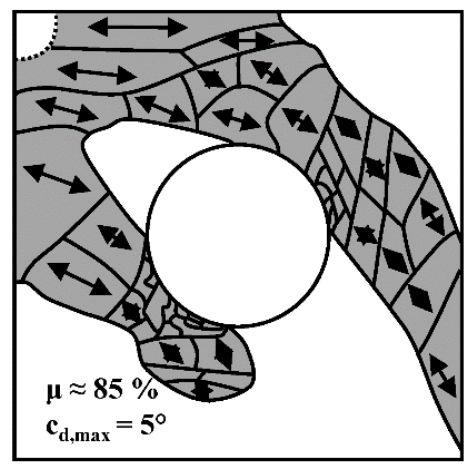

(f)

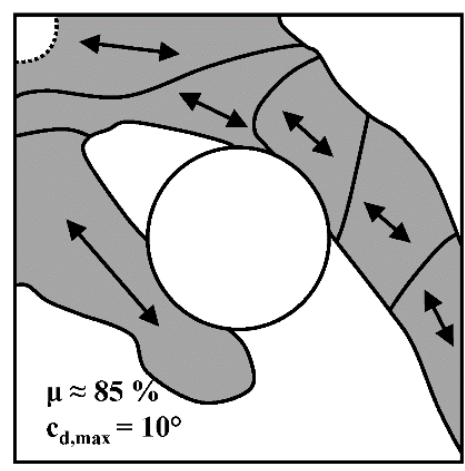

(i)

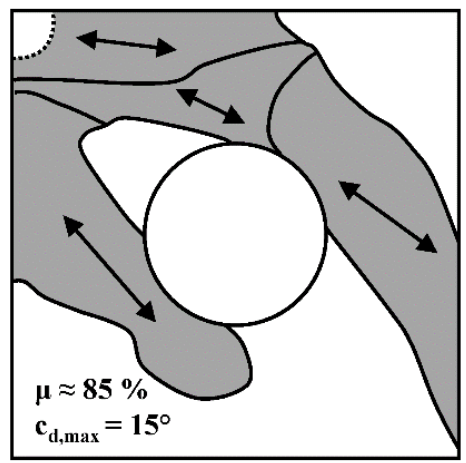

Figure 13. Illustration of the clusters and homogenized angles for the demonstration example. Results for deviation factors of $c_{d, \text { max }}=5^{\circ}, c_{d, \text { max }}=10^{\circ}$, and $c_{d, \text { max }}=15^{\circ}$ for stress thresholds $\mu=50 \%, \mu=67.5 \%$, and $\mu=85 \%$ are shown in (a-i). Grey areas indicate reinforcement areas. Angles for small clusters in $(\mathbf{b}, \mathbf{c})$ are not displayed.

In the example (square plate with hole), a non-linear stress distribution results within the component [31], as shown in Figure 1b. Hence, the relationship between the stress threshold and the reinforced area is not linear, i.e., a stress threshold of $\mu \approx 50 \%$ does not imply that half of the component area is covered by reinforcements (see Figure 13).

For values up to approx. $40 \%$, only a small share of the stresses and corresponding areas are identified as reinforcements by the mechanical model. This results in a significantly higher displacement compared to the reference laminate. However, costs and weight are also significantly lower. For large stress thresholds $(\mu>90 \%)$, the increase in weight and corresponding costs due to overlapping reinforcements are disproportionately large. Although this reduces the displacement to approx. $60 \%$, the weight and costs also increase by $50 \%$. Furthermore, the results in Figure 12 show that the material costs of the considered 
carbon fiber are the main cost influence and are directly dependent on the stress threshold. This behavior can be derived from the strong correlation of costs with component weight. The second most critical cost factor are the stacking costs for the reinforcements, influenced by the deviation factor allocated to the clusters.

\section{Conclusions}

This paper presents an approach of combining novel models for structural design and cost estimation. By generating simplified TT concepts, the rapid identification of the most promising concepts regarding cost, weight, and stiffness is enabled.

The mechanical model is based on the split of the stress into the base-laminate and the reinforcements. By using a combination of a low-cost base-laminate and local reinforcements, economically and mechanically optimized TT concepts can be realized. Using the mechanical model, a concept for the reinforcements is established within a few seconds, based on only a single isotropic FEA. Extending this model using a simplified cost estimation, an objective and early staged decision about the potential of the considered case is conduced.

By analyzing a generic demonstration example, feasible settings for the main parameters of stress threshold and deviation factor, and regarding the target values of cost, weight, and max. displacement are identified. The investigations showed that both param'eters have a substantial influence on these target values. Cost, weight, and max. displacement can be reduced by about $20 \%$. The stress threshold and deviation factor can be chosen in a way such that weight and cost are reduced by $30 \%$ with the same max. displacement, or the max. displacement is reduced by $30 \%$ with the same weight and costs. Any settings in-between are possible, allowing the creation of customized TT concepts for individual requirements.

The proposed approach can be performed within a few minutes, since the models can be executed semi-automatically. Thus, this integrated approach can support a designer in the early phase of product development, during which changes to requests frequently occur.

\section{Outlook}

In the presented study, the layer thicknesses of both the base-laminate and reinforcements were defined manually. Setting the local thicknesses based on the mean stresses in each cluster holds an additional potential for improvement of the mechanical model. Furthermore, research is required to implement strength criteria for TT.

The mechanical model calculates clusters with relatively few elements, whose influence on the stiffness is questionable; though leading to increased manufacturing costs in the economic model. Research is required to investigate the effect of the optimum size of reinforcement areas. In addition, how overlapping areas affect the mechanical and economic properties must be examined.

In this study, the reinforcement areas were not fully adapted to production processes. Based on the coordinates, angles, and shape, the reinforcements can be adapted to any fiber composite manufacturing technology. The presented approach will be validated in extensive mechanical tests, to ensure its industrial applicability.

Author Contributions: Conceptualization, J.M.B., G.J., S.S. and J.S.; methodology, J.M.B., G.J., S.S. and J.S.; software, J.M.B. and S.S.; validation, J.M.B. and S.S.; formal analysis, J.M.B., S.S.; investigation, J.M.B. and S.S.; resources, J.M.B., G.J., S.S. and J.S.; data curation, J.M.B., G.J., S.S. and J.S.; writingoriginal draft preparation, J.M.B. and S.S.; writing-review and editing, J.M.B., G.J., S.S. and J.S.; visualization, J.M.B. and S.S.; supervision, G.J. and J.S.; project administration, G.J., S.S. and J.S. All authors have read and agreed to the published version of the manuscript.

Funding: This research has been carried out as part of the project "Tailored Composites", funding code 03VP04690 which is funded by the German Federal Ministry of Education and Research (BMBF).

Institutional Review Board Statement: Not applicable.

Informed Consent Statement: Not applicable. 


\section{Data Availability Statement: Not applicable.}

Conflicts of Interest: The authors declare no conflict of interest.

\section{References}

1. Konstruieren Mit Faser-Kunststoff-Verbunden; Springer: Berlin/Heidelberg, Germany, 2007; ISBN 978-3-540-72189-5.

2. Hyer, M.W.; Charette, R.F. Use of curvilinear fiber format in composite structure design. AIAA J. 1991, 29, 1011-1015. [CrossRef]

3. Lenz, C. Konzept Für Einen Modifizierten Produktentstehungsprozess von Faserverbundbauteilen zur Anwendung Integral Verstärkter Gewebe; Shaker: Aachen, Germany, 2017.

4. Hohmann, A.; Albrecht, S.; Lindner, J.P.; Wehner, D.; Kugler, M.; Prenzel, T. Recommendations for Resource Efficient and Environmentally Responsible Manufacturing of CFRP Products: Results of the Research Study MAI Enviro 2.0; Carbon Composites e.V: Augsburg, Germany, 2017; ISBN 978-3-9818900-0-6.

5. Azzi, V.D.; Tsai, S.W. Anisotropic strength of composites. Exp. Mech. 1965, 5, 283-288. [CrossRef]

6. Wang, H.W.; Zhou, H.W.; Gui, L.L.; Ji, H.W.; Zhang, X.C. Analysis of effect of fiber orientation on Young's modulus for unidirectional fiber reinforced composites. Compos. Part B Eng. 2014, 56, 733-739. [CrossRef]

7. Nikbakt, S.; Kamarian, S.; Shakeri, M. A review on optimization of composite structures Part I: Laminated composites. Compos. Struct. 2018, 195, 158-185. [CrossRef]

8. Wang, Z.; Sobey, A. A comparative review between Genetic Algorithm use in composite optimisation and the state-of-the-art in evolutionary computation. Compos. Struct. 2020, 233, 111739. [CrossRef]

9. Schmidt, J.; Jacobs, G.; Beger, A.-L. Resource-Efficient CFRP Design Methodology for Automotive Systems. In Proceedings of the ICCM International Conferences on Composite Materials, Xi'an, China, 20-25 August 2017.

10. Hu, W.; Park, D.; Choi, D. Structural optimization procedure of a composite wind turbine blade for reducing both material cost and blade weight. Eng. Optim. 2013, 45, 1469-1487. [CrossRef]

11. Kalantari, M.; Dong, C.; Davies, I.J. Effect of matrix voids, fibre misalignment and thickness variation on multi-objective robust optimization of carbon/glass fibre-reinforced hybrid composites under flexural loading. Compos. Part B Eng. 2017, 123, 136-147. [CrossRef]

12. De Munck, M.; de Sutter, S.; Verbruggen, S.; Tysmans, T.; Coelho, R.F. Multi-objective weight and cost optimization of hybrid composite-concrete beams. Compos. Struct. 2015, 134, 369-377. [CrossRef]

13. Park, C.H.; Lee, W.I.; Han, W.S.; Vautrin, A. Simultaneous optimization of composite structures considering mechanical performance and manufacturing cost. Compos. Struct. 2004, 65, 117-127. [CrossRef]

14. Pelletier, J.L.; Vel, S.S. Multi-objective optimization of fiber reinforced composite laminates for strength, stiffness and minimal mass. Comput. Struct. 2006, 84, 2065-2080. [CrossRef]

15. Senouci, A.B.; Al-Ansari, M.S. Cost optimization of composite beams using genetic algorithms. Adv. Eng. Softw. 2009, 40, 1112-1118. [CrossRef]

16. Walker, M.; Smith, R.E. A technique for the multiobjective optimisation of laminated composite structures using genetic algorithms and finite element analysis. Compos. Struct. 2003, 62, 123-128. [CrossRef]

17. Mittelstedt, M.; Hansen, C.; Mertiny, P. Design and Multi-Objective Optimization of Fiber-Reinforced Polymer Composite Flywheel Rotors. Appl. Sci. 2018, 8, 1256. [CrossRef]

18. Kelly, D.W.; Elsley, M. A procedure for determining load paths in elastic continua. Eng. Comput. 1995, 12, 415-424. [CrossRef]

19. Moldenhauer, H. Die Orthotrope Wärmeleitung Als Numerischer Integrator Allgemeiner Richtungsfelder Mit Anwendung Zur Optimalen Faserplatzierung und Kraftflussvisualisierung; Karlsruher Institut für Technologie (KIT): Karlsruhe, Germany, 2016.

20. Reuschel, D.; Mattheck, C. Three-dimensional fibre optimisation with computer aided internal optimisation. Aeronaut. J. 1999, 103, 415-420. [CrossRef]

21. Klein, D.; Malezkiw, W.; Wartzack, S. Introduction of a computational approach for the design of composite structures at the early embodiment design stage. In Design for Life, Proceedings of the 20th International Conference on Engineering Design (ICED 15), Politecnico di Milano, Italy, 27-30 July 2015; Weber, C., Husung, S., Cantamessa, M., Cascini, G., Marjanovic, D., Graziosi, S., Eds.; Design Society: Glasgow, UK, 2015; ISBN 978-1-904670-69-8.

22. Hagnell, M.K.; Åkermo, M. A composite cost model for the aeronautical industry: Methodology and case study. Compos. Part B Eng. 2015, 79, 254-261. [CrossRef]

23. Schubel, P.J. Cost modelling in polymer composite applications: Case study-Analysis of existing and automated manufacturing processes for a large wind turbine blade. Compos. Part B Eng. 2012, 43, 953-960. [CrossRef]

24. Ehrlenspiel, K.; Hundal, M.S.; Kiewert, A.; Lindemann, U. Cost-Efficient Design; Springer: Berlin/Heidelberg, Germany, 2007; ISBN 978-3-540-34648-7.

25. Pedersen, P. Optimal Orientation of Anisotropic Materials Optimal Distribution of Anisotropic Materials Optimal Shape Design with Anisotropic Materials Optimal Design for a Class of Non-Linear Elasticity. In Optimization of Large Structural Systems; Rozvany, G.I.N., Ed.; Springer: Dordrecht, The Netherlands, 1993; pp. 649-681, ISBN 978-94-010-9579-2.

26. Rolfes, R.; Teßmer, J.; Degenhardt, R.; Temmen, H.; Bürmann, P.; Juhasz, J. New Design Tools for Lightweight Aerospace Structures. In Progress in Computational Structures Technology; Topping, B., Mota Soares, C.A., Eds.; Saxe-Coburg Publications: Stirlingshire, UK, 2004; pp. 1-30, ISBN 1-874672-21-0. 
27. Voelkl, H.; Wartzack, S. Design for Composites: Tailor-made, bio-inspired topology optimization for fiber-reinforced plastics. In Proceedings of the DESIGN 15th International Design Conference, Faculty of Mechanical Engineering and Naval Architecture, University of Zagreb, Zagreb, Croatia, 21-24 May 2018; The Design Society: Glasgow, UK, 2018; pp. 499-510.

28. Moldenhauer, H. Berechnung variabler Faserverläufe zur Optimierung von Compositestrukturen. Lightweight Des. 2011, 4, 51-56. [CrossRef]

29. Likas, A.; Vlassis, N.; Verbeek, J.J. The global k-means clustering algorithm. Pattern Recognit. 2003, 36, 451-461. [CrossRef]

30. Narayana Naik, G.; Gopalakrishnan, S.; Ganguli, R. Design optimization of composites using genetic algorithms and failure mechanism based failure criterion. Compos. Struct. 2008, 83, 354-367. [CrossRef]

31. Toubal, L.; Karama, M.; Lorrain, B. Stress concentration in a circular hole in composite plate. Compos. Struct. 2005, 68, 31-36. [CrossRef] 